\title{
$\infty$
}

\section{Highly Sensitive Cholesterol Sensors Using Mixture of Cholesterol Oxidase and ZnO Nanoparticles on Plastic}

\author{
Sukhyung Park, Kyoungah $\mathrm{Cho}^{\dagger}$, and Sangsig Kim ${ }^{\dagger}$ \\ Department of Electrical Engineering, Korea University, Seoul 136-713, Korea
}

Received December 27, 2012; Revised December 11, 2013; Accepted March 24, 2014

In this study, cholesterol sensors consisting of a mixture of cholesterol oxidase (ChOx) and zinc oxide (ZnO) nanoparticles (NPs) are constructed on plastic substrates and their sensing characteristics are examined in air. The current of the ChOx-ZnO NP film decreases in magnitude as cholesterol molecules are adsorbed on the film, due to the resulting increase in the number of electrons generated by the reaction between the cholesterol and the ChOx. The cholesterol sensor shows a high sensitivity of $1.08 \mu \mathrm{A} / \mathrm{mM}$ and a wide detection range from $10 \mathrm{nM}$ to $1 \mathrm{mM}$.

Keywords: Plastic sensor, Cholesterol, Biosensor

\section{INTRODUCTION}

Recently inorganic materials have attracted considerable attention in the fabrication of biosensors owing to their excellent electrical properties and chemical stability [1-4]. Metal oxides have been used in performance-enhanced biosensors [5-7]. Among the various metal oxides, zinc oxide $(\mathrm{ZnO})$ is one of the most suitable materials for biosensors because of its nontoxicity, good biocompatibility, and electrocatalytic activity [810]. On the other hand, most biosensor measurements have been performed in aqua-based solutions. However, the measurement process is more cumbersome than in air because of environmental considerations such as salvation [11]. The convenience associated with biosensor measurements could expand the scope of their practical application. In contrast to most organic semiconductor-based biosensors, inorganic semiconductor-based biosensors permit the electrical properties to be measured in air. In this study, the performance was evaluated for a cholesterol sensor made of a biocomposite consisting of $\mathrm{ZnO}$ nanoparticles (NPs) having a size of $70 \mathrm{~nm}$ and cholesterol oxidase (ChOx) in air. ZnO NPs have a higher surface-to-volume ratio than other $\mathrm{ZnO}$ nanostructures. Thus,

${ }^{\dagger}$ Author to whom all correspondence should be addressed: E-mail: chochem@korea.ac.kr, sangsig@korea.ac.kr

Copyright (O2014 KIEEME. All rights reserved.

This is an open-access article distributed under the terms of the Creative Commons Attribution Non-Commercial
License (http://creativecommons.org/licenses/by-nc/3.0) which permits unrestricted noncommercial use distribution, and reaproduction in any medium, provided the original work is properly cited
and (a)

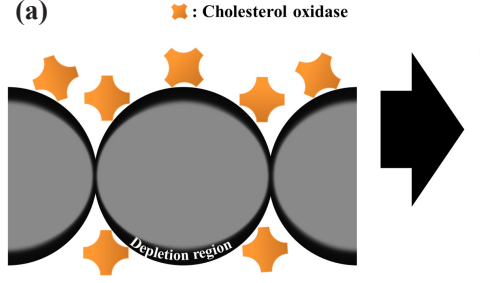

:Cholesterol

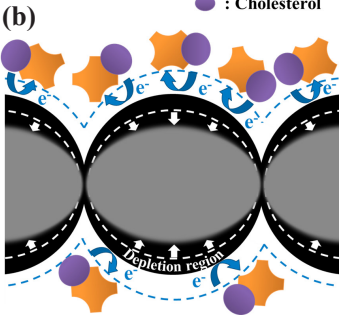

Fig. 1. Schematic of sensing mechanism for our cholesterol sensors designed in this study. (a) A channel of the ChOx-ZnO NP film and (b) extended the depletion regions after the cholesterol solution is added to the ChOx-ZnO NP film channel.

ZnO NPs provide more adsorption sites for ChOx to react with cholesterol.

Figure 1 shows a schematic of the sensing mechanism for our cholesterol sensor designed in this study. The NPs are adjacent to each other in the ChOx-ZnO NP film, as illustrated in Fig. 1(a). The voltage applied across the two electrodes causes a current to flow via electron tunneling through the potential barriers between the NPs. The depletion region at the surface of the film, produced from a mixture of $\mathrm{ChOx}$ and $\mathrm{ZnO}$ NPs, is extended by the electrical field of electrons generated by the reaction between $\mathrm{ChOx}$ and cholesterol as follows [12]. 


$$
\begin{aligned}
\text { Choesterol }+\mathrm{O}_{2} \stackrel{\text { chox }}{\longrightarrow} & \text { Cholest }-4-\text { en-3-one }+\mathrm{H}_{2} \mathrm{O}_{2} \\
\mathrm{H}_{2} \mathrm{O}_{2} & \rightarrow \mathrm{O}_{2}+2 \mathrm{H}^{+}+2 e^{-}
\end{aligned}
$$

The current for the ChOx-ZnO NP film decreases proportionally with the number of cholesterol molecules.

In this study, in order to confirm the availability of ZnO NPs for convenient high-efficiency biosensors, we fabricate the cholesterol sensor using ZnO NPs and investigate its sensing performance via the electrical properties to be measured in air.

\section{EXPERIMENTS}

All reagents were purchased from Sigma-Aldrich. The solution of ChOx was prepared in de-ionized water $(1 \mathrm{mg} / \mathrm{mL})$. The commercial ZnO NPs, with an average diameter of about $70 \mathrm{~nm}$, were dispersed in methanol $(0.05 \mathrm{~g} / \mathrm{mL})$. The solution of ChOx (10 $\mu \mathrm{L})$ was mixed with $\mathrm{ZnO}$ NPs dispersed in methanol $(50 \mu \mathrm{L})$. The cholesterol sensors were fabricated on a polyethersulfone (PES) plastic substrate. First, gold electrodes with a channel width of $50 \mu \mathrm{m}$ were deposited by thermal evaporation on the plastic substrate and the mixture of ChOx and ZnO NPs was spin-coated on the electrodes. Then, cholesterol dissolved in butanol was spotted on the film made of the mixture of ChOx and ZnO NPs by means of a nano-plotter (GeSiM; NP2.1E), specifically for lowvolume liquid handling. The cholesterol solutions were prepared with concentrations ranging from $10 \mathrm{nM}$ to $1 \mathrm{mM}$. In each case, 10 drops of the solution, each with a volume of $0.3 \mathrm{~nL}$, were dropped onto the film made of ChOx-ZnO NPs. The film made of ChOx-ZnO NPs was characterized by FTIR spectroscopy (FTIR, Varian 640-IR). The electrical properties of the cholesterol sensor were measured in air at room temperature with an Agilent HP 4155C.

\section{RESULTS AND DISCUSSION}

Figure 2 shows the FTIR spectra of the (a) ZnO NPs, (b) the ChOx, and (c) the mixture of ChOx and ZnO NP in the range of $500 \sim 4,000 \mathrm{~cm}^{-1}$. The strong absorption at $524 \mathrm{~cm}^{-1}$ indicates the band stretching of $\mathrm{Zn}$ and $\mathrm{O}$ in $\mathrm{ZnO}$ and the characteristic amide $\left(1,542\right.$ and $\left.1,654 \mathrm{~cm}^{-1}\right)$ and amino acid $(2,850$ and 2,919 cm $\left.{ }^{1}\right)$ bands of the proteins of ChOx are shown in Figs. 2(a) and 2(b), respectively $[13,14]$. The amide bands are assigned to the C-N stretching and $\mathrm{C}=\mathrm{H}$ stretching vibration modes and the amino acid bands correspond to the $\mathrm{C}-\mathrm{H}$ stretching in the methyl group. The peak corresponding to the $\mathrm{Zn}-\mathrm{O}$ stretching is shifted to $551 \mathrm{~cm}^{-1}$ in the mixture of $\mathrm{ZnO}$ and $\mathrm{ChOx}$, as shown in Fig. 2(c), which is attributed to the electrostatic interactions between $\mathrm{ChOx}$ and $\mathrm{ZnO}$ [15]. In the mixture of $\mathrm{ZnO}$ and $\mathrm{ChOx}$, the $\mathrm{C}-\mathrm{O}$ $\left(1,037 \mathrm{~cm}^{-1}\right)$ and N-H $\left(3,286 \mathrm{~cm}^{-1}\right)$ stretching bands of the amide are observed. These observations reveal good miscibility between the $\mathrm{ChOx}$ and the $\mathrm{ZnO}$ solutions.

The current-voltage curves are exhibited in Fig. 3 for the ChOx$\mathrm{ZnO}$ NP film as a function of the cholesterol concentration. The current in the ChOx-ZnO NP film decreases as the concentration of the cholesterol solution increases, which is consistent with the sensing mechanism demonstrated in Fig. 1. As indicated in the equation for the reaction of $\mathrm{ChOx}$ and cholesterol, the electrons are generated from the reaction. The number of the generated electron is directly proportional to the concentration of cholesterol. Thus, the current is reduced depending on the concentration of cholesterol added to the ChOx-ZnO NP film. The electric field of electrons generated by the reaction between the cho-

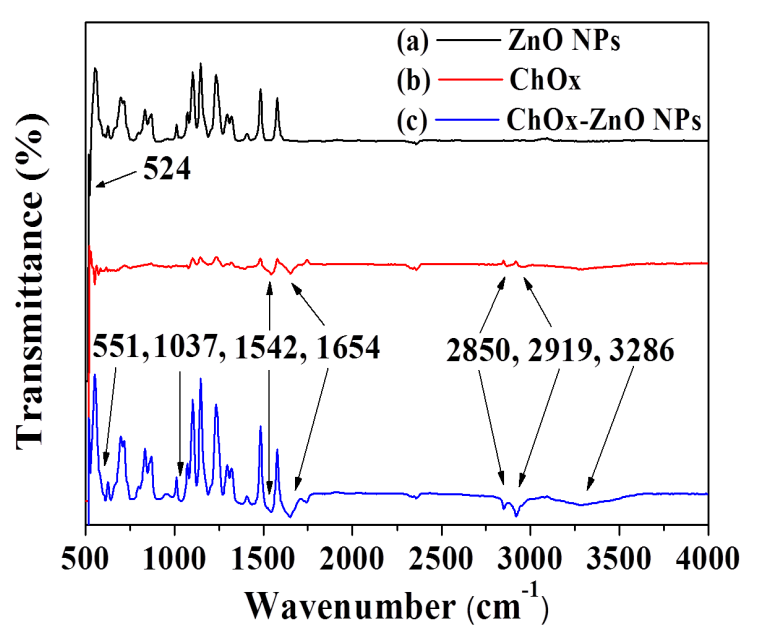

Fig. 2. FT-IR spectra of films made of (a) ZnO NPs, (b) ChOx, and (c) the mixture of ChOx and $\mathrm{ZnO}$ NPs.

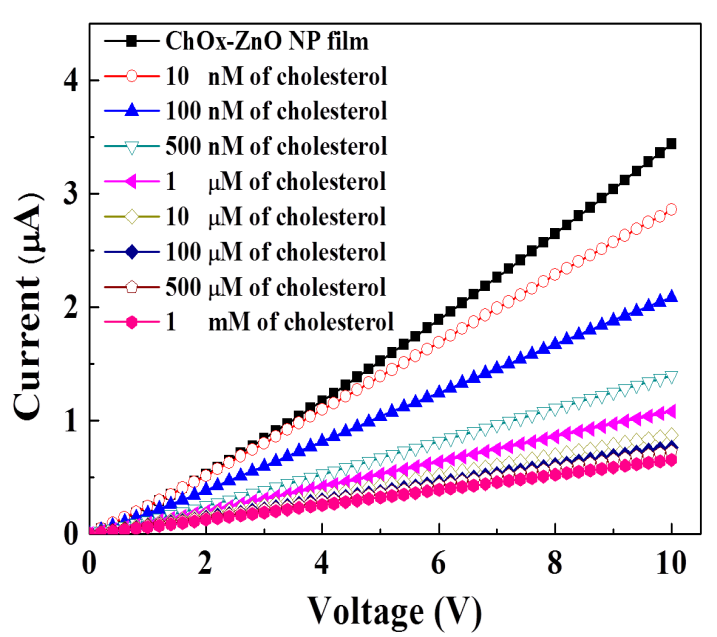

Fig. 3. The current-voltage characteristics of the ChOx-ZnO NP film cholesterol sensor as a function of the conc entrations of added cholesterol.

lesterol molecules and ChOx causes the depletion region to be extended.

As the concentration of cholesterol increases from $10 \mathrm{nM}$ to 1 $\mathrm{mM}$, the current decreases from 2.8 to $0.6 \mu \mathrm{A}$ at $10 \mathrm{~V}$. The detection range of our cholesterol sensor is wider than that of the cholesterol sensors based on $\mathrm{ZnO}$ nanorods chemically grown on $\mathrm{Ag}$ wires $(1 \mu \mathrm{M}$ to $10 \mathrm{mM})[16]$.

Figure 4 represents the plot of the current versus the concentration of cholesterol at $10 \mathrm{~V}$. At low concentrations of cholesterol (10 $\mathrm{nM}$ to $1 \mu \mathrm{M}$ ), the magnitude of the current decreases linearly with increasing cholesterol concentration, whereas it decreases more gently at high concentrations above $1 \mu \mathrm{M}$. This phenomenon can be attributed to the limited amount of ChOx responsive to the cholesterol molecules. The linear detection range extends from $10 \mathrm{nM}$ to $1 \mu \mathrm{M}$, and the linear regression equation is established as follows; $y=-1.795 x+2.879$, where $y$ is the current $(\mu \mathrm{A})$ and $\mathrm{x}$ is the cholesterol concentration. The correlation coefficient (R) is estimated to be $\mathrm{R}=0.965$. Compared to prior cholesterol sensors based on $\mathrm{ZnO}$, our sensor is superior in the detection range (10 $\mathrm{nM}$ to $1 \mathrm{mM})$ and the sensitivity $\left(270 \mu \mathrm{A} \cdot \mathrm{mM}^{-1} \cdot \mathrm{cm}^{-2}\right)$. The sensitivity is higher than the cholesterol sensors based on $\mathrm{Al}$ doped $\mathrm{ZnO}$ thin film $\left(173 \mu \mathrm{A} \cdot \mathrm{mM}^{-1} \cdot \mathrm{cm}^{-2}\right.$, representing perhaps 


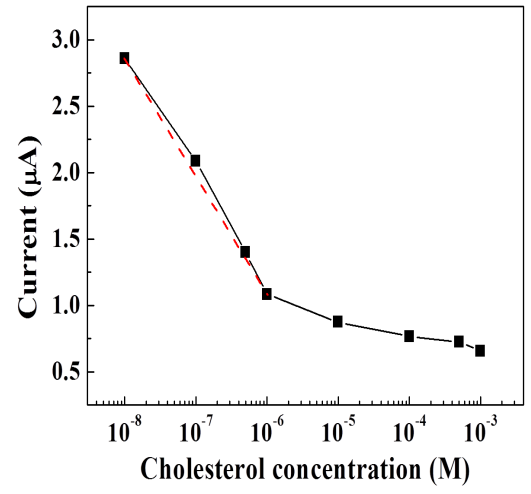

Fig. 4. Current as a function of the concentration of added cholesterol. The linear detection range is marked by a dashed line.

the highest known sensitivity [17]. The detection range of our cholesterol sensor is wider than the cholesterol sensors based on the solution-gate field effect transistor consisting of $\mathrm{ZnO}$ nanorods ( $1 \mu \mathrm{M}$ to $45 \mathrm{mM})$ [18]. Moreover, considering a recent study on the cholesterol sensors using $\mathrm{ZnO}$ nanotubes in which the sensitivity is $79.4 \mu \mathrm{A} \cdot \mathrm{mM}^{-1} \cdot \mathrm{cm}^{-2}$ and the detection range is from $1 \mu \mathrm{M}$ to $15 \mathrm{mM}$ [19]. Thus, the sensing performance of our cholesterol sensor is superior to other cholesterol sensors based on $\mathrm{ZnO}$. The high surface-to-volume ratio of ZnO NPs, used as the channel material, provides the excellent sensing performance of our cholesterol sensor.

In comparison to emerging cholesterol sensors using chitosan, our cholesterol sensor has a high sensitivity $(1.08 \mu \mathrm{A} / \mathrm{mM})$ and a low detection limit (10 nM). More recently, a cholesterol sensor made of chitosan nanofibers and gold NPs showed a selectivity of $1.02 \mu \mathrm{A} / \mu \mathrm{M}$ and detection limit of $0.5 \mu \mathrm{M}$ [20]. Consequently, the characteristics of our cholesterol sensor measured in air are superior to those of the other sensors measured in aqua-based solutions [21,22].

\section{CONCLUSIONS}

In the study, we fabricated cholesterol sensors made of a mixture of ChOx and ZnO NPs on a plastic substrate and examined their sensing capabilities in air at room temperature. The current of the ChOx-ZnO NP film decreases as cholesterol molecules are adsorbed on the film. The presence of electrons, generated from the reaction between cholesterol and $\mathrm{ChOx}$, reduces the current of the ChOx-ZnO NP film by widening its depletion region after a cholesterol solution is dropped on the film. These cholesterol sensors exhibited high sensitivity $(1.08 \mu \mathrm{A} / \mathrm{mM})$ and a wide detection range extending from $10 \mathrm{nM}$ to $1 \mathrm{mM}$. These new cholesterol sensors offer the potential of fabricating high-performance biosensors for convenient operation in air.

\section{ACKNOWLEDGMENTS}

This research was supported by the Basic Science Research Program (NRF-2012R1A1A2042104), the Mid-career Researcher Program (NRF-2012R1A2A2A01045613) through the National Research Foundation of Korea (NRF) funded by the Ministry of Education, Science and Technology.

\section{REFERENCES}

[1] H. Tao, X. Wang, X. Wang, Y. Hu, Y. Ma, Y. Lu, Z. Hu, J. Nanosci. Nanotechnol. 10, 860 (2010 [DOI: http://dx.doi.org/10.1166/ jnn.2010.1799].

[2] K. G. Lee, R. Wi, T. J. Park, S. H. Yoon, J. Lee, S. J. Lee, D. H. Kim, Chem. Commun. 46, 6374 (2010) [DOI: http://dx.doi. org/10.1039/c0cc00762e].

[3] P. Benvenuto, A. K. M. Kafi, A. Chen, J. Electroanal Chem. 627, 76 (2009) [DOI: http://dx.doi.org/10.1016/ j.jelechem.2008.12.022].

[4] X. Cao, N. Wang, L. Wang, C. Mo, Y. Xu, X. Cai, L. Guo, Sens. Actuator B-Chem. 147, 730 (2010) [DOI: http://dx.doi. org/10.1016/j.snb.2010.03.087].

[5] A. Kaushik, P. R. Solanki, A. A. Ansari, G. Sumana, S. Ahmad, B. D. Malhotra, Sens. Actuator B-Chem. 138, 572 (2009) [DOI: http:// dx.doi.org/10.1016/j.snb.2009.02.005].

[6] M. Kocanda, I. Abdel-Motaleb, J. Appl. Phys. 108, 076103 (2010) [DOI: http://dx.doi.org/10.1063/1.3483947].

[7] S. Kaneko, T. Ito, Y. Hirabayashi, T. Ozawa, T. Okuda, Y. Motoizumi, K. Hirai, Y. Naganuma, M. Soga, M. Yoshimoto, K. Suzuki, Talanta 84, 579 (2011).

[8] A. Fulati, S. M. U. Ali, M. H. Asif, N. H. Alvi, M. Willander, C. Brännmark, P. Stralfors, S. I. Börjesson, F. Elinder, B. Danielsson, Sens. Actuator B-Chem. 150, 673 (2010) [DOI: http://dx.doi. org/10.1016/j.snb.2010.08.021].

[9] Z. Yang, X. L. Zong, Z. Ye, B. Zhao, Q. Wang, P. Wang, Biometerials 31, 7534 (2010) [DOI: http://dx.doi.org/10.1016/ j.biomaterials.2010.06.019].

[10] J. Zhao, D. Wu, J. Zhi, Bioelectrochemistry 75, 44 (2009) [DOI: http://dx.doi.org/10.1016/j.bioelechem.2009.01.005].

[11] M. Shamsipur, M. Najafi, M. M. Hosseini, Bioelectrochemistry 77, 120 (2010) [DOI: http://dx.doi.org/10.1016/ j.bioelechem.2009.07.007].

[12] P. Norouzi, F. Faridbod, E. Nasli-Esfahani, B. Larijani, M. R. Ganjali, Int. J. Electrochem. Sci. 5, 1008 (2010).

[13] J. Zheng, R. Ozisik, R. W. Siegel, Polymer 46, 10873 (2005) [DOI: http://dx.doi.org/10.1016/j.polymer.2005.08.082].

[14] S. P. Singh, S. K. Arya, P. Pandey, B. D. Malhotra, S. Saha, K. Sreenivas, V. Gupta, Appl. Phys. Lett. 91, 063901 (2007) [DOI: http://dx.doi.org/10.1063/1.2768302].

[15] P. R. Solanki, A. Kaushik, A. A. Ansari, B. D. Malhotra, Appl. Phys. Lett. 94, 143901 (2009) [DOI: http://dx.doi. org/10.1063/1.3111429].

[16] M. Q. Israr, J. R. Sadaf, M. H. Asif, O. Nur, M. Willander, B. danielsson, Thin Solid Films 519, 1106 (2010) [DOI: http://dx.doi. org/10.1016/j.tsf.2010.08.052].

[17] N. Batra, M. Tomarb, and V. Gupta, J. Appl. Phys. 112, 114701 (2012) [DOI: http://dx.doi.org/10.1063/1.4768450].

[18] R. Ahmada, N.Tripathy, Y. Hahn, Biosens. Bioelectron 45, 281 (2013) [DOI: http://dx.doi.org/10.1016/j.bios.2013.01.021].

[19] R. Ahmad, N. Tripathy, S. H. Kim, A. Umar, A. Al-Hajry, and Y. Hahn, Electrochem. Commun. 38, 4 (2014) [DOI: http://dx.doi. org/10.1016/j.elecom.2013.10.028].

[20] P. Gomathi, D. Ragupathy, J. H. Choi, J. H. Yeum, S. C. Lee, J. C. Kim, S. H. Lee, H. D. Ghim, Sens. Actuator B-Chem. 153, 44 (2011) [DOI: http://dx.doi.org/10.1016/j.snb.2010.10.005].

[21] A. l. Gopalan, K. P. Lee, D. Ragupathy, Biosens. Bioelectron. 24, 2211 (2009) [DOI: http://dx.doi.org/10.1016/j.bios.2008.11.034].

[22] C. Zhao, L. Wan, L. Jiang, Q. Wang, K. Jiao, Anal. Biochem. 383 25 (2008) [DOI: http://dx.doi.org/10.1016/j.ab.2008.08.022]. 